\title{
A SURVEY OF HIV AND HCV AMONG FEMALE PRISON INMATES IN PORTUGAL
}

\author{
Henrique Barros ${ }^{1,2}$, Elisabete Ramos ${ }^{2}$, Raquel Lucas $^{2}$ \\ ${ }^{1}$ National Coordination for HIVIAIDS, Lisbon, Portugal \\ 2Department of Hygiene and Epidemiology, University of Porto Medical School, Porto, Portugal
}

\section{SUMMARY}

HIV and hepatitis $\mathrm{C}$ virus (HCV) monitoring among prison inmates is instrumental in countries with concentrated HIVIAIDS epidemics. Knowledge on these dynamics in imprisoned women in Portugal is scarce.

The HIV and HCV prevalence was estimated among inmates in the largest Portuguese prison for women, which holds $57 \%$ of all female inmates in Portugal, according to sociodemographic and behavioural variables and characterised attitudes towards HIVIAIDS according to serological status.

Collected variables included age, education, country of birth, penal status, and accumulated time in prison. Drug injection and sharing of injection material were inquired, as well as age at first sexual intercourse. Inmates also characterised their attitudes towards HIVIAIDS. A venous blood sample was collected and tested for anti-HIV and anti-HCV antibodies.

In this sample of 445 female inmates, 10\% were HIV-positive, while $11 \%$ were HCV-positive. Longer imprisonment periods were associated with relatively higher HCV prevalence and women with later ages at first sexual intercourse were less frequently HIV-positive, regardless of drug injecting behaviour. HIV prevalence was $44 \%$ in women who had ever injected drugs and $6 \%$ in those who had never injected. HCV frequency was $69 \%$ among injecting drug users (IDUs) and 4\% among non-IDUs. In women who injected drugs both HIV and HCV were more frequent when the number of injections was higher and when women reported sharing of injection material. Similar attitudes towards HIV/AIDS were found for HIV-positive and negative women, but those living with HIV had more tolerant positions.

This study emphasizes the role of injecting drug use in the transmission of HIV and HCV in women in Portuguese prisons and reinforces the need for the systematic adoption of harm reduction measures.

Key words: prisons, HIVIAIDS, hepatitis C, women's health, Portugal

Address for correspondence: H. Barros, National Coordination for HIVIAIDS, Palácio Bensaúde, Estrada da Luz, 153, 1600-153 Lisboa, Portugal. E-mail: hbarros@sida.acs.min-saude.pt

\section{INTRODUCTION}

In 2005 Portugal presented the second highest rate of HIV cases in Western and Central Europe, 251 cases per million population, which is particularly notable when seen in the European Union context, where this estimate was on average 67.2 cases per million (1). The Portuguese HIV epidemic has a concentrated pattern, with prevalence below $1 \%$ in the general population and above $5 \%$ among injecting drug users (IDUs) and prison inmates (2). In the latter group, HIV frequency increased from $1 \%$ in 1987 to $16 \%$ in $2002(3,4)$. The 2005 prevalence reported by prison services was $10.4 \%$ in men and $7.2 \%$ in women (5). In the same year, infection by hepatitis $\mathrm{C}$ virus (HCV) was present in $21.7 \%$ of male inmates and $6.3 \%$ of female inmates.

Prison inmates are increasingly recognised as an important monitoring target for HIV and HCV, not only due to a growing concern about prison health but also considering inmates' dynamic link to the rest of the society. Over one quarter of convictions in
Portugal is due to drug-related crimes, which emphasizes the expected role of drug injection behaviour in the transmission of these infections among the imprisoned population (5).

International studies show that the fraction of women among prison populations is increasing (6), an observation which brings about further issues in prison health, such as those of gender equity and women's health. In addition, there is lack of information on the extent to which drug use can account for HIV transmission among women. Information on the frequency of HIV/HCV co-infection and on the correlates of these infections in imprisoned women is also scarce. The monitoring of HIV and HCV prevalence among women inmates, as well as the collection of second generation indicators is a useful measure of the status of the epidemic, particularly in countries with such concentrated patterns as those seen in Portugal, and may be regarded as a predictor of future trends in the transmission of disease.

In this study we estimated the prevalence of HIV and HCV infection in female inmates in the largest Portuguese prison for 
women according to sociodemographic and behavioural variables. The study also aimed at characterising women's attitudes towards HIV/AIDS according to their HIV serological status.

\section{MATERIAL AND METHODS}

In this study, we used data collected in 2005 as part of a survey of two Portuguese prisons (one holding mainly female inmates and the other only male inmates), which comprised a self-administered questionnaire and the collection of a venous blood sample. This study describes the population in the female prison (Estabelecimento Prisional de Tires), which alone holds $57 \%$ of all women in Portuguese prisons. Sociodemographic data in the questionnaire included gender, age, formal education, marital status, country of birth, and parents' nationality. Information on penal status (preventive imprisonment or conviction) and on life accumulated time spent in prison was collected. Regarding ever and previous month use of psychoactive substances and frequency of use, inmates were questioned about smoking and drinking habits, and use of illicit drugs (cannabis, heroin, cocaine, amphetamines, ecstasy, and anabolic steroids without medical prescription). Injection of drugs and sharing of injection material were inquired, as well as the specific material shared. Information on history of sexual intercourse, age at first intercourse and number of partners throughout life was collected. Inmates also answered questions on the importance of HIV/AIDS, their personal concern about the issue, and whether or not they had sufficient information on the subject. Additionally, attitudes towards people living with HIV/AIDS were assessed by classifying participants' agreement with the statements "HIV-infected children should attend the same school as other children" and "HIV-infected people can carry out their job in the same workplace as their colleagues”.

A venous blood sample was collected and tested for anti-HIV and anti-HCV antibodies.

The study objectives and protocol were explained in detail by a team of trained health professionals unrelated to the institution. Individuals were asked to sign a written informed consent document if they agreed to participate and anonymity was assured by assigning each inmate with a sequentially generated confidential 4-digit number with which both the questionnaire and the blood sample were identified. Completion of the questionnaire and blood sample collection were assisted by the above-mentioned health professionals who were also responsible for the provision of individual pre- and post-test counselling. Inmates who tested positive were referred to the HIV/AIDS and infectious diseases clinic in the prison. Women whose HCV test was positive were referred to the gastroenterology unit in the same clinic.

In December 2005 there were 875 women in Portuguese prisons of which the majority was in Tires. In this study, 502 women agreed to answer the questionnaire, which corresponds to $57.4 \%$ of the total number of imprisoned women in the country (5). Among these, 445 accepted to have a blood sample drawn. Participants for whom blood was drawn were not significantly different from those who refused this procedure regarding age, education or history of injecting drugs. In our sample, $49.1 \%$ of women were aged 25 to 39 years and $39.0 \%$ had less than five years of formal education. Inmates born in Portugal represented $57.6 \%$ of the sample, $28.2 \%$ were preventively imprisoned, and
$58.3 \%$ had one to six years of accumulated time in prison. In the present analysis, results were stratified according to whether or not women reported having ever injected drugs (10.8\% of inmates had injected drugs).

\section{RESULTS}

In the present sample 9.9\% (95\% CI: 7.3-13.0) of women were HIV-positive, while 10.8\% (95\% CI: 8.1-14.0) were HCVpositive, and 4.7\% (95\% CI: 2.9-7.1) had both HIV and HCV markers of infection.

\section{Prevalence among Non-IDU}

HIV prevalence among women who reported never having injected drugs was 5.7\% (95\% CI: 3.5-8.5), HCV prevalence was 3.5\% (95\% CI: $1.9-5.9)$, and 1.4\% (95\% CI: $0.4-3.1)$ were coinfected (Table 1). Among inmates who had never injected drugs, $60 \%$ of HIV-positive women referred their positive serologic status during the questionnaire, while $54 \%$ of $\mathrm{HCV}$-infected inmates were aware of their status. HIV and HCV were more frequent in older women (respectively $7 \%$ and $6 \%$ in $40-69$-year-olds vs.

Table 1. Prevalence of HIV and HCV in women who reported having never injected drugs, according to socio-demographic and behavioural variables

\begin{tabular}{|c|c|c|c|c|}
\hline & Total & HIV* & $\mathrm{HCV}^{*}$ & $\begin{array}{c}\text { HIV/HCV } \\
\text { co-infection }\end{array}$ \\
\hline & $\mathrm{n}$ & n (\%) & n (\%) & $\mathrm{n}(\%)$ \\
\hline Total & 370 & $21(5.7)$ & $13(3.5)$ & $5(1.4)$ \\
\hline \multicolumn{5}{|l|}{ Age (years) } \\
\hline$<25$ & 56 & $1(1.8)$ & $0(0.0)$ & $0(0.0)$ \\
\hline 25-39 & 174 & $11(6.3)$ & $5(2.9)$ & $2(1.1)$ \\
\hline $40-69$ & 133 & $9(6.8)$ & $8(6.0)$ & $3(2.3)$ \\
\hline \multicolumn{5}{|l|}{ Marital status } \\
\hline single & 227 & $14(6.2)$ & $8(3.5)$ & $3(1.3)$ \\
\hline not single & 138 & $4(4.4)$ & $5(3.6)$ & $2(1.4)$ \\
\hline \multicolumn{5}{|l|}{ Formal education (years) } \\
\hline$<5$ & 149 & $8(5.4)$ & $7(4.7)$ & $3(2.0)$ \\
\hline $5-8$ & 74 & $9(12.2)$ & $3(4.0)$ & $0(0.0)$ \\
\hline$>8$ & 141 & $3(2.1)$ & $3(2.1)$ & $2(1.4)$ \\
\hline \multicolumn{5}{|l|}{ Country of birth } \\
\hline Portugal & 199 & $12(6.0)$ & $10(5.0)$ & $4(2.0)$ \\
\hline other country & 162 & $8(4.9)$ & $3(1.8)$ & $1(0.6)$ \\
\hline \multicolumn{5}{|l|}{ Presently convicted } \\
\hline no & 106 & $6(5.7)$ & $1(0.9)$ & $0(0.0)$ \\
\hline yes & 251 & $14(5.6)$ & $12(4.8)$ & $5(2.0)$ \\
\hline \multicolumn{5}{|l|}{ Life time in prison (years) } \\
\hline$<1$ & 93 & $5(5.4)$ & $1(1.1)$ & $1(1.1)$ \\
\hline $1-6$ & 200 & $11(5.5)$ & $6(3.0)$ & $1(0.5)$ \\
\hline $6-25$ & 51 & $4(7.8)$ & $6(11.8)$ & $3(5.9)$ \\
\hline \multicolumn{5}{|c|}{ Age at rst sexual intercourse (years) } \\
\hline$<14$ & 29 & $2(6.9)$ & $1(3.4)$ & $0(0.0)$ \\
\hline $14-17$ & 217 & $15(6.9)$ & $8(3.7)$ & $5(2.3)$ \\
\hline$>17$ & 108 & $4(3.7)$ & $3(2.8)$ & $0(0.0)$ \\
\hline
\end{tabular}

* including HIV/HCV co-infections 
$5 \%$ and $2 \%$ in women under 40 years-old). The prevalence of $\mathrm{HIV}$ and HCV was lowest in women in the highest formal education category ( $2 \%$ for both infections) when compared to the figures found for those with up to eight schooling years (8\% and $4 \%$, respectively). Compared to those born outside of Portugal, inmates born in Portugal were more frequently infected by HIV and/or HCV ( $6 \%$ vs. $5 \%$ of HIV prevalence, $5 \%$ vs. $2 \%$ of HCV prevalence, and $2 \%$ vs. $1 \%$ of coinfection). HIV prevalence was similar between women in preventive prison and those who were convicted (6\%), but HCV was more frequent in convicted inmates ( $5 \%$ vs. $1 \%$ in preventive detainees). Women with longer accumulated periods of imprisonment were more likely to be HIV or HCV infected ( $8 \%$ and $12 \%$, respectively). Additionally, inmates who reported their first sexual intercourse at earlier ages more frequently tested positive for HIV and/or HCV. (HIV prevalence: $7 \%$, HCV prevalence: $4 \%$, coinfection prevalence: $2 \%$ ).

Table 2. Prevalence of HIV and HCV in women who reported having injected drugs, according to socio-demographic and behavioural variables

\begin{tabular}{|c|c|c|c|c|}
\hline & Total & HIV* & $\mathrm{HCV}^{*}$ & $\begin{array}{l}\text { HIVIHCV } \\
\text { co-infection }\end{array}$ \\
\hline & $\mathrm{n}$ & n (\%) & $\mathrm{n}(\%)$ & $\mathrm{n}(\%)$ \\
\hline Total & 45 & $20(44.4)$ & $31(68.9)$ & $15(33.3)$ \\
\hline \multicolumn{5}{|l|}{ Age (years) } \\
\hline$<25$ & 3 & $2(66.7)$ & $2(66.7)$ & $1(33.3)$ \\
\hline $25-39$ & 27 & $12(44.4)$ & $19(70.4)$ & $9(33.3)$ \\
\hline $40-69$ & 14 & $5(35.7)$ & $9(64.3)$ & $4(28.6)$ \\
\hline \multicolumn{5}{|l|}{ Marital status } \\
\hline single & 30 & $12(40.0)$ & $24(80.0)$ & $10(33.3)$ \\
\hline not single & 14 & $7(50.0)$ & $6(42.9)$ & $4(28.6)$ \\
\hline \multicolumn{5}{|l|}{ Formal education (years) } \\
\hline$<5$ & 9 & $4(44.4)$ & $5(55.6)$ & $3(33.3)$ \\
\hline $5-8$ & 14 & $6(42.9)$ & $9(64.3)$ & $4(28.6)$ \\
\hline$>8$ & 21 & $9(42.9)$ & $16(76.2)$ & $7(33.3)$ \\
\hline \multicolumn{5}{|l|}{ Country of birth } \\
\hline Portugal & 37 & $14(37.8)$ & $26(70.3)$ & $12(32.4)$ \\
\hline other country & 7 & $5(71.4)$ & $5(71.4)$ & $3(42.9)$ \\
\hline \multicolumn{5}{|l|}{ Presently convicted } \\
\hline no & 7 & $2(28.6)$ & $6(85.7)$ & $2(28.6)$ \\
\hline yes & 37 & $17(46.0)$ & $25(67.6)$ & $13(35.1)$ \\
\hline \multicolumn{5}{|l|}{ Life time in prison (years) } \\
\hline$<1$ & 9 & $3(33.3)$ & 7 (77.8) & $2(22.2)$ \\
\hline $1-6$ & 23 & $11(47.8)$ & $16(69.6)$ & $9(39.1)$ \\
\hline 6-25 & 11 & $5(45.4)$ & $8(72.7)$ & $4(36.4)$ \\
\hline \multicolumn{5}{|c|}{ Age at rst sexual intercourse (years) } \\
\hline$<14$ & 7 & $4(57.1)$ & $3(42.9)$ & $2(28.6)$ \\
\hline $14-17$ & 28 & $15(53.6)$ & $21(75.0)$ & $12(42.9)$ \\
\hline$>17$ & 9 & $1(11.1)$ & $6(66.7)$ & $1(11.1)^{\prime}$ \\
\hline \multicolumn{5}{|c|}{ Lifetime estimated number of injections } \\
\hline$<40$ & 12 & $2(16.7)$ & $2(16.7)$ & $0(0.0)$ \\
\hline$\geq 40$ & 33 & $18(54.6)$ & $29(87.9)$ & $15(45.4)$ \\
\hline \multicolumn{5}{|c|}{ Ever shared injection material } \\
\hline no & 17 & $4(23.5)$ & $9(52.9)$ & $2(11.8)$ \\
\hline yes & 27 & $16(57.1)$ & $22(78.6)$ & $13(46.4)$ \\
\hline
\end{tabular}

* including HIV/HCV co-infections

\section{Prevalence among IDU}

Regarding inmates who reported having injected drugs, $44.4 \%$ (95\% CI: 29.6-60.0) were HIV-positive, while 68.9\% (95\% CI: 53.4-81.8) were HCV-infected, and 33.3\% (95\% CI: 20.0-49.0) were HIV/HCV co-infected (Table 2). Awareness of HIV serologic status was reported by $68 \%$ of the infected women and HCV infection was acknowledged by $62 \%$ of those infected. Among IDU, HIV prevalence decreased with age (68\% in women under 25 years old vs. 36\% in 40-69 years old) and HCV was more frequent among 25-39 years old (70\%). HIV prevalence was similar across education classes (range: $43 \%$ to $44 \%$ ) but $\mathrm{HCV}$ was more prevalent among inmates with a higher education level (76\% among women with 9 or more schooling years vs. $61 \%$ in those under 9 years of formal education). Inmates born outside Portugal were more frequently HIV-infected (71\% vs. 38\%), though no such difference was found for HCV (71 \% vs. 70\%). Women with one to six years of total imprisonment period were more often HIV-positive (48\%) and HCV was more frequent in inmates who reported less than one year of total imprisonment period (78\%). The estimated number of injections throughout life was associated with both HIV ( $\geq 40$ injections: $55 \%$ vs. $<40$ injections: $17 \%$ ) and HCV ( $\geq 40$ injections: $88 \%$ vs. $<40$ injections: $17 \%)$ frequencies. Among women who reported having shared injection material $57 \%$ were HIV-positive (vs. $24 \%$ of those who had not shared material), and 79\% were HCV-positive (vs. 53\% of those who had not shared material). HIV was less prevalent among inmates who were over 17 years old at the time of their first sexual intercourse (11\% vs. $54 \%$ in those who were 17 years old or younger) while HCV was less frequent among those whose first sexual intercourse happened before the age of 14 (43\% vs. $73 \%$ in those who were over 13 ).

\section{Attitudes towards HIV/AIDS}

When analysing women's attitudes towards HIV/AIDS according to their serological status we found that nearly all women considered HIV/AIDS a very important issue (all HIV-positive and $99 \%$ of the HIV-negative) (Table 3). However, HIV-infected women were more frequently very concerned about the matter than non-infected women (98\% vs. $81 \%$ ). The proportion of women who considered they had sufficient information on the subject was similar in both groups and lower than $60 \%$. Regarding attitudes towards people living with HIV, infected women were more tolerant about children living with HIV attending the same school as other children (92\% agreed vs. 78\%) and about people living with HIV sharing workplace with other people (90\% agreed vs. 83\%).

\section{DISCUSSION}

\section{HIV and HCV Frequency in Portuguese Prisons}

Previous results on the frequency of HIV in Portuguese prisons show an obvious increasing trend, from $1 \%$ in 1987 to $9 \%$ in 1996, 11\% in 1998 and 16\% in 2002 (3-5). However, these findings refer to gender-aggregated data, and should therefore be judiciously applied to women. In the Portuguese female inmates presently surveyed, $10 \%$ were HIV-positive, $11 \% \mathrm{HCV}$ and 5\% were HIV/HCV co-infected. These estimates are in agreement with the trend observed in previous studies, but higher than 
Table 3. Attitudes of inmates towards HIVIAIDS according to their HIV serological status

\begin{tabular}{|c|c|c|}
\hline & \multicolumn{2}{|c|}{ HIV serologic status } \\
\hline & Negative & Positive \\
\hline & $\mathrm{n}(\%)$ & $n(\%)$ \\
\hline \multicolumn{3}{|l|}{ Importance of AIDS } \\
\hline $\begin{array}{r}\text { very important } \\
\text { slightly important } \\
\text { not important at all } \\
\end{array}$ & $\begin{array}{c}386(98.5) \\
3(0.8) \\
3(0.8)\end{array}$ & $\begin{array}{c}42(100.0) \\
0(0.0) \\
0(0.0)\end{array}$ \\
\hline \multicolumn{3}{|l|}{ Concern about AIDS } \\
\hline $\begin{array}{r}\text { very concerned } \\
\text { slightly concerned } \\
\text { not concerned at all }\end{array}$ & $\begin{array}{c}314(80.9) \\
44(11.3) \\
30(7.7)\end{array}$ & $\begin{array}{c}40(97.6) \\
1(2.4) \\
0(0.0)\end{array}$ \\
\hline \multicolumn{3}{|l|}{ Suf cient information about HIVIAIDS } \\
\hline $\begin{array}{r}\text { no } \\
\text { yes }\end{array}$ & $\begin{array}{l}159(40.3) \\
236(59.8)\end{array}$ & $\begin{array}{l}17(39.5) \\
26(60.5)\end{array}$ \\
\hline \multicolumn{3}{|c|}{ HIV-infected children should attend the same school as other children } \\
\hline $\begin{array}{l}\text { strongly agree/agree } \\
\text { neither agree nor disagree } \\
\text { disagree/strongly disagree }\end{array}$ & $\begin{array}{c}294(77.6) \\
4(1.1) \\
81(21.4)\end{array}$ & $\begin{array}{c}36(92.3) \\
0(0.0) \\
3(7.7)\end{array}$ \\
\hline \multicolumn{3}{|c|}{$\begin{array}{l}\text { HIV-infected people can carry out their job in the same } \\
\text { workplace as their colleagues }\end{array}$} \\
\hline $\begin{array}{l}\text { strongly agree/agree } \\
\text { neither agree nor disagree } \\
\text { disagree/strongly disagree }\end{array}$ & $\begin{array}{c}303(82.6) \\
7(1.9) \\
57(15.5)\end{array}$ & $\begin{array}{c}35(89.7) \\
1(2.6) \\
3(7.7) \\
\end{array}$ \\
\hline
\end{tabular}

those reported in 2005 by prison services for the 875 imprisoned women in the country (HIV: $7.2 \%, \mathrm{HCV}$ : $9.1 \%$ and HIV/HCV co-infection: $2.6 \%$ ) (5). This disparity may be attributable to different methodological approaches in the selection of inmates to be tested, given that HIV testing periodicity varies according to the criteria applied by each prison (5) while this study was conducted in one specific time period. Alternatively, it may be due to some degree of selection bias, since we included only one prison, even though it houses over half of the female inmates in Portugal. Indeed, although the age distribution was similar to the national data, our sampling overrepresented inmates in preventive prison (28\% in this study vs. $24 \%$ in the country) and those born in other countries (58\% vs. $20 \%$ ) (5). The latter is probably due to the fact that $52 \%$ of the documented foreign citizens are concentrated in Lisbon, where the prison under study is located (8).

\section{Awareness of HIV and HCV Serological Status}

We found that one third to a half of HIV-positive or HCVpositive inmates did not report their infection status in the questionnaire. This result may be partly explained by voluntary underreporting which we cannot measure in this study because information on awareness was not validated. However, it is likely that to some extent there is a real underestimation of HIV and $\mathrm{HCV}$ infections in Portuguese prisons.

\section{Drug Injection Behaviour}

As expected, substantial differences were found in HIV and HCV prevalence according to whether or not women had injected drugs. Among inmates who reported never having used injected drugs, HIV prevalence was especially low under 25 years of age.
As in those who had injected drugs, women with later ages at the first sexual intercourse were less frequently HIV-positive. Longer imprisonment periods were associated with relatively higher $\mathrm{HCV}$ prevalence and with HIV/HCV co-infection. Some degree of underreporting of injecting and sharing behaviour is predictable and may account for the otherwise high prevalence of HCV among women who reported never having injected. Nevertheless, when considering the low prevalence of HIV/HCV co-infection (1.4\%) among these women, our findings suggest a substantial role for sexual transmission of HIV, since in three quarters of HIV-positive women HCV was absent.

In women who reported drug injection, of whom one third was $\mathrm{HIV} / \mathrm{HCV}$ co-infected, the disparity regarding HIV frequency between those born in Portugal and those born in other countries is noteworthy, particularly when the similarity of HCV prevalence is considered. Additionally, HIV was more common in convicted inmates, which may be partly due to more serious offences being associated with other HIV risk factors, namely those related to drugs and to the accumulated time in prison. Both HIV and HCV were markedly more frequent when the reported lifetime number of injections was high and when women admitted to having shared injection material. Although a variety of behavioural traits may play a role as determinants, the comparatively low frequency of HIV in women whose first sexual intercourse occurred later in life suggests that even among women who injected drugs, sexual intercourse may account for part of the transmission.

Overall, our results confirm that injecting drug use is frequent and represents the major mode of HIV transmission among female prisoners in Portugal. Indeed, injecting drug use constituted the most frequent mode of transmission when all notified HIV cases up to June 2007 were evaluated (44.4\%) (9). We could hypothesize that injecting habits were a consequence of imprisonment, although this seems unlikely when taking into account that $27 \%$ of all convictions in Portugal are related to illicit drugs. Studies conducted in different European countries have shown that the prevalence of HIV among inmates who use injected drugs reflects the frequency of the agent among the non-imprisoned population sharing the same type of exposures and living in the same geographical area (10). In 2005, regional HIV prevalence among clients of drug treatment centres, both genders taken together, ranged between $12 \%$ and $22 \%$ (regardless of injection behaviour), which suggests that similar estimates should be found in prisons (11). In fact, in a serological survey of another Portuguese prison published in 2004, HIV prevalence was 6\% among all inmates but ascended to $14.5 \%$ in those who admitted using injected drugs (12). The cross-sectional nature of this study does not allow us to determine if the seroconversion occurred prior to the first imprisonment.

\section{Harm Reduction in Portuguese Prisons}

In Portugal, although harm reduction programmes in prisons were legislated in 1999 (12), it has not been systematically put into practice, rather it is relying on policies of individual prisons. Indeed, countrywide specific measures have not yet been implemented in Portuguese prisons and the treatment of addiction remains the main concern - the prison surveyed in this study, has implemented opioid substitution therapy (OST) and drug-free units, focusing on drug dependence treatment, rather than on needle and syringe exchange programmes (NEP) (3). In January 
2006, a national plan aiming at preventing and controlling infectious diseases in prisons was defined (5). It included a number of technical recommendations for future legislation, namely regarding access to harm reduction programmes (OST and NEP were proposed), prevention and treatment modalities, continuous education of prison staff and cooperation with non-governmental organizations. Priority was set upon the implementation of a syringe exchange programme, currently taking place in two prison settings and to be extended to all prisons in the future, based on the results of the ongoing pilot phase (5).

\section{Attitudes towards HIV/AIDS}

In this study, when comparing women who were HIV-positive and HIV-negative we found considerable similarities regarding attitudes towards HIV/AIDS. Nearly all women in both groups considered HIV/AIDS a very important issue, and similar proportions (approximately 40\%) believed that they did not have sufficient information about the infection. The level of effectiveness of counselling seems to be similar among HIV-positive and HIV-negative women, either by insufficient coverage or due to lack of efficacy. Particularly in HIV-positive inmates, and especially if considering that the majority of them were aware of their serological status, this finding is of key importance. These results may be interpreted in the context of the Portuguese general population, in view of a recent survey of adults where misconceptions about HIV/AIDS were frequent (15). As expected, the main differences in attitudes between HIV-infected and non-infected inmates include the degree of concern expressed (HIV-positive women being more frequently very concerned about HIV/AIDS) and discriminatory attitudes, particularly towards children living with HIV/AIDS, where HIV-positive women were substantially more tolerant.

In this study we did not assess the need for or access to treatment among HIV-positive inmates. According to prison services, $56.9 \%$ of the infected inmates in 2005 were on antiretroviral treatment but there is no information on which fraction of those in need was under treatment (5). There is growing awareness on the important role that prison inmates have in the dynamics of HIV and HCV as members of a society from which they are separated and to which the majority returns. This study has assessed the extent to which HIV and HCV are present in women in Portuguese prisons, as well as their relation to sociodemographic and behavioural aspects, namely use of injected drugs.

\section{CONCLUSION}

Although there may be limited generalizability, the results we obtained emphasize the role of injecting drug use in the transmission of HIV and HCV in women in Portuguese prisons and reinforce the need for the systematic adoption of harm reduction measures, for which effectiveness has been thoroughly proven (16). Our findings may additionally be used as baseline indicators which enable the estimation of the impact of future prevention, treatment and control strategies.

\section{Acknowledgements}

Special appreciation is due to the Portuguese Prison Services, and to A. Meliço Silvestre, F. Amaro, and G. Poças, who were instrumental in launching this study.

This study was funded by Fundaçăo Calouste Gulbenkian and Comissăo Nacional de Luta contra a Sida.

\section{REFERENCES}

1. EuroHIV. HIV/AIDS Surveillance in Europe. End-year report 2006. No. 75. Saint-Maurice: French Institute for Public Health Surveillance; 2007.

2. National Coordination for HIV/AIDS [homepage on the Internet]. Activity report May 2007 [cited 2008 Jan 15]. Available from: www.sida.pt. (In Portuguese.)

3. General Prison Directorate [homepage on the Internet]. Lisbon: Ministry of Justice [cited 2007 Nov 27]. Available from: http://www.dgsp.mj.pt/. (In Portuguese.)

4. Torres A, Gomes M. Drugs and prisons in Portugal. Lisbon: CIES/ISCTE; 2002. (In Portuguese.)

5. Justice/Health Working Group. National action plan to fight the transmission of infectious diseases in prisons. Despacho conjunto no. 72/2006. Lisbon: Ministry of Justice; 2006. (In Portuguese.)

6. Hatton DC, Kleffel D, Fisher AA. Prisoners' perspectives of health problems and healthcare in a US women's jail. Women Health. 2006;44(1):119-36.

7. Portuguese Ombudsman. Our prisons II - special report by the Portuguese Ombudsman to the Parliament. Lisbon: Portuguese Ombudsman; 2003. (In Portuguese.)

8. Statistics Portugal (INE). Highlight: foreign population in Portugal 2005. Lisbon: INE; 2006. (In Portuguese.)

9. Centre for the Epidemiological Surveillance of Communicable Diseases [homepage on the Internet]. HIV/AIDS - the Portuguese situation on 30th June 2007 [cited 2007 Dec 12]. Available from: http://www.sida.pt. (In Portuguese.)

10. United Nations Office on Drugs and Crime. World Health Organization, Joint United Nations Programme on HIV/AIDS. HIV/AIDS prevention, care, treatment and support in prison settings: a framework for an effective national response. New York: United Nations; 2006.

11. Institute on Drugs and Drug Addiction. 2005 Annual Report: the Portuguese situation regarding drugs and drug addiction. Volume I. Lisbon: IDT; 2005. (In Portuguese.)

12. Passadouro R. Prevalence infections and risk factors due to HIV, Hepatitis B and C in a prison establishment in Leiria. Acta Med Port. 2004 SeptOct;17(5):381-4. (In Portuguese.)

13. Portuguese Parliament [document on the Internet]. Law 170/99. September 1999 [cited 2008 Jan 5]. Available from: http://www.gplp.mj.pt/ home/concluidos/L170-99.pdf. (In Portuguese.)

14. Portuguese Parliament [document on the Internet]. Law 3/2007. January 2007 [cited 2007 Sep 7]. Available from: http://www.idt.pt/media/legislacao/lei_3_07.pdf. (In Portuguese.)

15. Amaro F, Frazăo C, Pereira ME, da Cunha Teles L. HIV/AIDS risk perception, attitudes and sexual behaviour in Portugal. Int J STD AIDS. 2004 Jan;15(1):56-60.

16. World Health Organization. Status paper on prisons, drugs and harm reduction. Copenhagen: WHO Regional Office for Europe; 2005.

Received February 15, 2008 Accepted in revised form July 19, 2008 